\title{
Methodological Perspective for Assessing European Consumers' Awareness of Cybersecurity and Sustainability in E-Commerce
}

\author{
Idiano D'Adamo ${ }^{1, *(1)}$, Rocío González-Sánchez ${ }^{2}$, Maria Sonia Medina-Salgado ${ }^{2}(\mathbb{C}$ \\ and Davide Settembre-Blundo ${ }^{2}$ (D) \\ 1 Department of Computer, Control and Management Engineering, Sapienza University of Rome, Via Ariosto \\ 25, 00185 Rome, Italy \\ 2 Department of Business Administration (ADO), Applied Economics II and Fundamentals of Economic \\ Analysis, Rey Juan Carlos University, 28032 Madrid, Spain; rocio.gonzalez@urjc.es (R.G.-S.); \\ sonia.medina@urjc.es (M.S.M.-S.); davide.settembre@urjc.es (D.S.-B.) \\ * Correspondence: idiano.dadamo@uniroma1.it
}

check for updates

Citation: D'Adamo, I.; GonzálezSánchez, R.; Medina-Salgado, M.S.; Settembre-Blundo, D. Methodological Perspective for Assessing European Consumers' Awareness of Cybersecurity and Sustainability in E-Commerce. Sustainability 2021, 13, 11343. https://doi.org/10.3390/ su132011343

Academic Editor: Giuseppe Ioppolo

Received: 26 September 2021

Accepted: 11 October 2021

Published: 14 October 2021

Publisher's Note: MDPI stays neutral with regard to jurisdictional claims in published maps and institutional affiliations.

Copyright: (c) 2021 by the authors. Licensee MDPI, Basel, Switzerland. This article is an open access article distributed under the terms and conditions of the Creative Commons Attribution (CC BY) license (https:// creativecommons.org/licenses/by/ $4.0 /)$.

\begin{abstract}
The increasing European consumer awareness of cybersecurity and sustainability issues in e-commerce is raising key methodological concerns. In a field like this, still unexplored by scholars, it is crucial to identify reliable data as well as to choose the modalities of combining primary and secondary data. As the robustness of the outcome of a study on a complex issue is highly sensitive to the quality of the data used, this paper is a communication that aims to complement and support previously published empirical research. This communication describes the methodological path to collect, integrate, and process data from different sources to interpret European consumers' attitudes towards cybersecurity and sustainability during e-commerce. In fact, COVID-19 has driven many users to shop online, raising concerns especially about the security of digital transactions. Scientific studies analyzing these effects are still lacking in the literature and therefore this paper aims to fill this gap. The limits of a rigid dataset such as Eurostat's are overcome by integrating the results of European citizens' behavior during online purchases, with a survey that involved some experts appropriately selected by the research team. The combination of primary and secondary sources of data and the application of a hybrid methodological approach using MCDA (multi-criteria decision analysis) and a Likert scale allowed new information that fills some gaps in the literature to be extracted from the data. How European citizens correlate e-commerce with cybersecurity and sustainability emerged, thus providing important insights for decision-makers.
\end{abstract}

Keywords: cybersecurity; sustainability; e-commerce; consumers' awareness; methodology

\section{Summary}

This communication aims to complement and support previously published empirical research [1]. E-commerce was already a relevant phenomenon before COVID-19 [2], but its growing trend has become more evident due to the blocking situation the world has been experiencing [3]. The increase in the number of online commercial exchanges has become more widespread globally, and with it, the security risks of online transactions have also grown [4], also causing impacts on the sustainability of supply chains [5]. As highlighted in the work associated with this data descriptor [1], the effect of the pandemic on the evolution of e-commerce is a topic unexplored by scholars, particularly in aspects concerning cybersecurity and sustainability of e-commerce supply chains. The issue of integrated logistics is as crucial for large as for small and medium-sized enterprises, and the pandemic has highlighted the importance of having raw materials available [6-8].

This new reality forces companies to adapt their business models and governments to quickly understand regulatory needs. A better understanding of the current state of e-commerce is therefore not only necessary for scientific knowledge, but also a critical need for decision-making by public authorities and businesses $[9,10]$. This raises at least two 
questions: what this trend has been like in the European context and whether there are the same or new challenges limiting its further development, e.g., security of transactions and privacy.

To answer these questions, Eurostat has been identified as an essential source of open data. Moreover, its use should be promoted to achieve better descriptive cross-sectional studies in Europe. However, the information is incomplete in terms of getting a better picture of the problems and obstacles of online shopping. Consequently, primary data were collected through experts. To reduce subjectivity bias and to achieve judgements from a global rather than a particular perspective, experts with 10 years of experience were chosen later for the interviews. The analysis presented in this paper aims to fill the previously highlighted literature gap and therefore represents a new contribution to the current body of literature on e-commerce.

In terms of methodology, this study proposes a multi-criteria decision analysis (MCDA) and a Likert-scale survey with post-interviews. The multi-criteria analysis provides a comparability model that can be easily fed with Eurostat annual data, which is very useful for data-driven decision-making on e-commerce in Europe. With the information obtained in the survey, we can provide important insights into the importance of digitization and cybersecurity for the sustainable development of e-commerce in Europe.

The pandemic period has prompted researchers to investigate the relationship between sustainability and resilience, and there are many areas in which the relationship between these two topics is investigated [11-13]. The study that this communication intends to integrate [1] contributed to this direction by focusing on the context of e-commerce by formulating two research questions:

- RQ1: How do European countries perform comparatively in e-commerce?

- RQ2: What are the most important challenges to the further expansion of e-commerce?

In this context, this communication instead aims to emphasize the methodological approach that made it possible to answer the RQs, explaining the implications underlying the selection, processing, and integration of heterogeneous data from both primary and secondary sources. The hybrid methodological approach adopted in this research has already been tested in other studies $[14,15]$ to collect data from suitable web-based databases for their processing in order to investigate user behavior. The MCDA allowed for a comparison between the performances of different European countries (to answer RQ1), whereas the Likert scale survey was useful for clarifying the impediments and barriers perceived by consumers when shopping online (to answer RQ2). In this way, this hybrid method can be applied to process other datasets on European countries or regions made available by public or private databases such as Eurostat.

\section{Data Description}

Some academics might ask how you can write a good scientific article without a literature gap. Others might ask how you write one without identifying a good data set. In the approach of this e-commerce-focused line, it was obvious that this is a fast-growing topic $[16,17]$. The data proposed by Salesforce in its Shopping Index report for the first quarter of 2021 are significant: $+58 \%$ compared to the first quarter of 2020 [3]. An analysis of individual countries showed $+111 \%$ for Canada, followed by the Netherlands $(+108 \%)$, UK (+91\%), Italy (+78\%), and France (+71\%). However, our literature analysis showed that the topic of cybersecurity in e-commerce is an up-and-coming issue that has not yet produced a sufficiently solid theoretical body to unambiguously highlight knowledge gaps [1].

Given this scarcity of data, we thought of using Eurostat, which promotes the process of harmonization of statistical methodology among the states themselves. This tool was used in the literature [18,19] and was useful for comparing different countries [20,21]. On the Eurostat search engine, we looked for e-commerce as a keyword and we identified the following cascade process: within the topic "Science, technology, digital society" is "digital economy and society," which in turn presents "ICT usage in households and by 
individuals," and here we came to our keyword. There were 30 criteria divided into six categories (Figure 1):

- Internet purchases by individuals is proposed in the file "isoc_ec_ib20.xls" (provided as a supplementary file http:/ / doi.org/10.5281/zenodo.4769642).

- Internet purchases-goods or services is proposed in the file "isoc_ec_ibgs.xls" (provided as a supplementary file http:/ / doi.org/10.5281/zenodo.4769642).

- Internet purchases—origin of sellers is proposed in the file "isoc_ec_ibos.xls" (provided as a supplementary file http:/ / doi.org/10.5281/zenodo.4769642).

- Internet purchases—collaborative economy is proposed in the file "isoc_ec_ce_i.xls" (provided as a supplementary file http://doi.org/10.5281/zenodo.4769642).

- Internet purchases-money spent is proposed in the file "isoc_ec_ibm.xls" (provided as a supplementary file http:/ / doi.org/10.5281/zenodo.4769642).

- Financial activities over the Internet-money spent is proposed in the file "isoc_ec_ifizo.xls" (provided as a supplementary file http://doi.org/10.5281/zenodo.4769642).

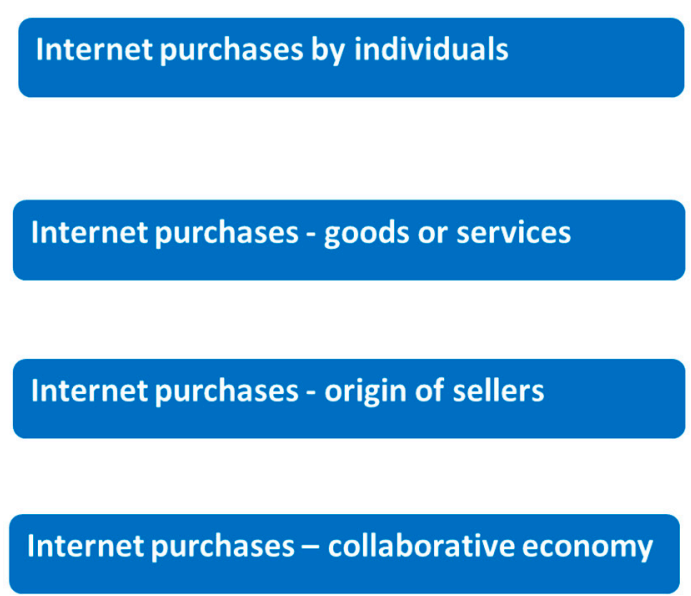

Internet purchases - money spent
Last online purchase: in the last 3 months

Last online purchase: in the 12 months

Frequency of online purchases in the last 3 months: 1 or $\mathbf{2}$ times

Frequency of online purchases in the last 3 months: 3 to 5 times

Frequency of online purchases in the last 3 months: 6 to 10 times

Frequency of online purchases in the last 3 months: more than 10 times

Online purchases (3 months): clothes (including sport clothing), shoes or accessories

Online purchases (3 months): furniture, home accessories or gardening products

Online purchases ( 3 months): printed books, magazines or newspapers

Online purchases ( 3 months): deliveries from restaurants, fast-food chains, catering services

Online purchases ( 3 months): music as a streaming service or downloads

Online purchases ( 3 months): films or series as a streaming service or downloads

Online purchases (3 months): from national sellers

Online purchases ( 3 months): from sellers from other EU countries
- Online purchases ( 3 months): from sellers of the rest of the world (non-EU countries)

Online purchases ( 3 months): from sellers from other countries (EU or non-EU)

Online purchases ( 3 months) from private persons: any physical goods

Online purchases ( 3 months) from private persons: household services

Online purchases (3 months) from a private person: transport service

Online purchases ( 3 months) from a private person: rented accommodation

Online purchases (3 months) from a private person: goods, household services, transport services or rented accommodation

- Online purchases in the last 3 months for less than 50 euro

Online purchases (3 months) for between 100 and 499 euro

Online purchases ( 3 months) for between 500 and 999 euro

Online purchases ( 3 months) for 1000 euro or more

Financial activities over the internet

Online purchases ( 3 months): insurance policies, including travel insurance, also as a package together with e.g. a plane ticket

- Online purchases ( 3 months): took a loan, mortgage or arranged credit from banks or other financial providers Online purchases ( 3 months): bought or sold shares, bonds, units in funds or other financial assets Online purchases (3 months): at least one of the financial activities (I_BFIN_SH1, I_BFIN_IN1, I_BFIN_CR1)

Figure 1. List of criteria.

Eurostat is a database in which data are proposed in multiple ways, and this is clearly an advantage. We highlighted the following hypothesis during our analysis:

- The presence of data for 2020 is a positive since the data are as recent as possible, but this was not the case for all items. There were no values for previous years, so we could not perform a trend analysis.

- The average value of EU 27 is proposed, but after analyzing the list of all countries there were some absences. These are very significant because both Italy and France, as shown above, had very significant values. However, these absences did not affect the results of the other countries, considering the presence of the Netherlands, which had an even more significant margin of growth, or how the intermediate values were calculated according to the most significant performance (associated with the leading country). 
- All data are reported in percentages, which allows for comparability across criteria. This led to two distinct observations. The first concerns the fact that the values are expressed in such a way as not to make distinctions based on the population numbers that characterize the individual countries. In an alternative case, the values could be divided according to specific variables (e.g., the number of inhabitants, the gross domestic product). The second concerns the unit of measurement, since if there were multiple, a way would have had to be found to make them comparable. The solution was in the normalization process. However, this choice was made because we wanted to give a replicable model in other contexts.

The aggregation of these data allowed for the calculation of values to measure the performance of all criteria for each of the 25 European countries examined. Within the same Excel files proposed above, the weights associated with all criteria are also reported. Unlike the values, these data were not identified through Eurostat. The procedure used was to calculate the number of views through the Google search engine. The keywords used from time to time were the specific names of the different criteria. More details will be provided below in the methodology section. Given that the different criteria were not aggregated all together but were evaluated on a category-by-category basis, the specific names of the different categories were used as keywords in this phase as well. This choice was motivated as follows:

- The definition of weights can typically be achieved by collecting data from a panel of respondents, who are chosen on the basis of their experience. In this context, experts' knowledge plays a key role. In some contexts, it is appropriate to choose specific categories of stakeholders. This approach is based on a scenario constructed to obtain the required data. Alternatively, another approach is one in which already available data are captured. It is the approach used in this work that is based on the number of views. However, the number of views is not always a positive element and therefore a feedback operation is necessary. In our case study, no hostile factors were detected.

- The definition of weights should be based on multiple approaches. Too many times in the literature there are works that analyze only a baseline scenario in which the output is proposed as a function of the chosen inputs. This has the limitation of not considering the variability of the results achieved. The construction of alternative scenarios allows, instead, relevance to be given to demonstrate how the output varies as a function of changes in inputs. This led to the identification of an alternative scenario, in which the weights of the categories were all considered of equal relevance.

- The surveys refer to April 2021. Changing the time frame can obviously change the number of views.

The data proposed above were identified to analyze RQ1. The next step was to identify the data useful for investigating RQ2. The identification of problems and barriers affecting Internet shopping could be gleaned from the literature or from field experiments designed to capture the critical issues highlighted by people. Based on the same method used in the previous step of the research, it was found that these aspects were already present in Eurostat and it seemed logical to use the same source. Consequently, all the potential responses that were proposed in the database were chosen, both for what concerns the problems that people have encountered when shopping on the Internet (Figure 2), and for what concerns the barriers, that is, the motivations that do not push people to make purchases on the Internet (Figure 3). 
INDIVIDUALS WHO ENCOUNTERED THE FOLLOWING PROBLEM WHEN MAKING PURCHASES OVER THE INTERNET:

Difficulties concerning guarantees

Speed of delivery longer than indicated

Delivery costs higher than indicated

Final price higher than indicated

Delivery costs or final price higher than indicated

\section{Wrong goods delivered}

Damaged goods delivered

Wrong or damaged goods delivered

\section{Wrong or damaged good/services delivered}

Lack of security of payments
Problems with fraud

Complaints and redress were difficult

No satisfactory response received after complaint

Complaints and redress were difficult or no satisfactory response received

Other

No problems

Technical failure

Difficulties finding information concerning guarantees, other legal rights

For private use

Foreign retailer did not sell in my country

Figure 2. Problems encountered by individuals when buying/ordering over the Internet.

\section{INDIVIDUALS WHO HAVEN'T ORDERED GOODS OR SERVICES OVER THE INTERNET, BECAUSE:}

They have no need

They prefer to shop in person, they like to see product, loyalty to shops or force of habit

For their own private use (relevant information about goods difficult to find on website)

They lack the necessary skills

It's too expensive

Of too long delivery times

Of problems receiving the ordered goods at home

Of too long delivery times / due to the problematic to receive the ordered goods at home

For their own private use (Payment security concerns)
For their own private use (Privacy concerns)

Of security concerns, they are worried about giving credit card details over the internet

\section{Of privacy concerns, they are worried about giving} personal details over

I'm worried about giving credit card or personal details over the internet

Of trust concerns about receiving or returning goods, complaint/redress

\section{They don't have a payment card}

The speed of the internet connection is too low

Of other reasons

The foreign retailer did not sell in my country

Figure 3. Perceived barriers to buying/ordering over the Internet.

At this stage of the work, it emerged that the data were proposed as a time trend and the latest reference year was 2019; however, several data were missing. Clearly this was generating an imbalance. For this reason, the hypothesis of comparing the different 
answers at the level of a single country was no longer valid and a panel of experts was used. Below are some hypotheses:

- RQ2 could have declined not in a general way, but at the level of each individual country. This output would have been useful because that way it would have been possible to highlight possible links with the results obtained in RQ1.

- The set of answers proposed by Eurostat turned out to be complete because it considered 20 possible answers to potential problems encountered when buying on the Internet and 18 possible answers relative to barriers. In the same way as the previous point, this analysis should not have turned out to be the same for all the markets. This leads to future directions of work, where the different answers proposed in this work can be complemented by specificities of individual sectors.

Our dataset concerns the responses that experts assigned by applying a Likert scale and are proposed in the following files:

- Problems encountered by individuals when buying/ordering over the Internet is proposed in the file "Problems.xlsx" (provided as a supplementary file http:/ / doi. org/10.5281/zenodo.4769642).

- Perceived barriers to buying/ordering over the Internet is proposed in the file "Barriers.xlsx" (provided as a supplementary file http:/ / doi.org/10.5281/zenodo.4769642).

To share our datasets, we used Zenodo, the multidisciplinary Open Access archive of research publications and data, the result of the collaboration between Cern and the OpenAire project [22]. It allows for self-archiving also for researchers of institutions that do not have institutional repositories. Each dataset is assigned a DOI, a standard identifier that associates any intellectual property object to its reference data (metadata).

\section{Methods}

The work was built on a cross-mix of methodologies (Figure 4). The first used was MCDA, which is widely used both in the literature and in the decision-making processes of the private and public sectors [23,24]. Related to this, some authors have employed a multi-criteria decision analysis model integrating both user preferences and expert opinions to support consumption decisions in an e-commerce environment [25]. Its strength is represented by the ability to make a synthesis from a multiplicity of data. It can compare multiple and conflicting alternatives, but it is also well suited to assess alternatives represented by territorial realities, such as countries, regions, and cities. The best alternative is the one that has the highest score, since each alternative has an associated score that is obtained through a product between the values associated with the individual criteria and the weights combined with the same criteria.

MCDA results are represented by the calculation of a performance value (PV), obtained as product between a row vector (RV), composed by the values of the criteria $(\mathrm{J})$, and a column vector $(\mathrm{CV})$, composed by the weights of the criteria. PV is calculated for each alternative (represented by single member states (MSs)) aggregating $\mathrm{N}$ criteria.

$$
\mathrm{PV}_{(\mathrm{MS})}=\sum_{\mathrm{J}=1}^{\mathrm{N}} \mathrm{RV}_{(\mathrm{MS})} * \mathrm{CV}
$$

The definition of the values, as explained in the previous section, saw the data defined based on Eurostat. The definition of the weights, on the other hand, was assumed to be based on the number of views. Here, however, it is worth focusing on the choice of calculating a global priority associated with each criterion that was calculated as the product of a local priority and a category priority [26]. This work considered two scenarios: (i) different weights (DW), in which the number of views in the Google search engine determined both local and category priority, and (ii) hybrid equal weights (HEW), in which all category priorities had the same weight, whereas local priority was calculated as in the DW scenario. 
E-COMMERCE

RQ1: A comparison among European countries

$$
\text { MCDA }
$$

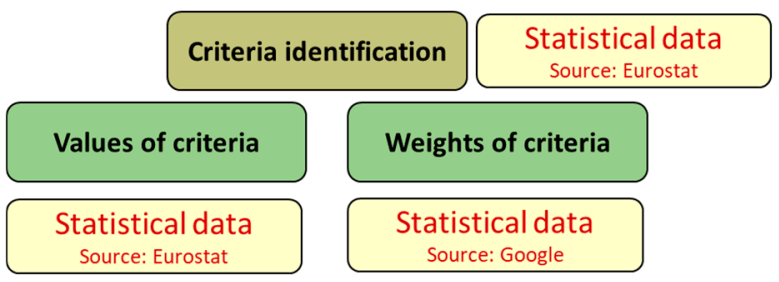

Ranking of European countries

Aggregated data
RQ2: Assessment of problems and barriers

Likert Scale Survey

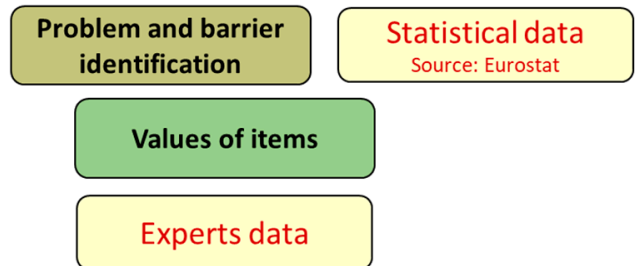

Ranking of items

Aggregated data

Sustainability
TOPIC

IDENTIFICATION

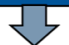

RQS DEFINITION

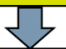

METHODOLOGY

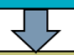

INPUT

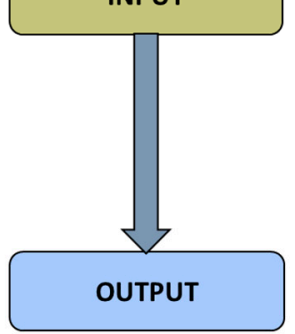

Cyber security

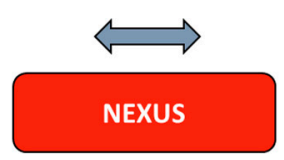

Figure 4. General framework.

Regarding the DW scenario, the first phase consisted of evaluating for each category a weight assigned to the various criteria that characterized it (called local priority). The second phase consisted of evaluating the various categories and the following weights were recorded (called category priority) based on the number of views: (i) Internet purchases by individuals $(4.0 \%)$, (ii) Internet purchases-goods or services $(15.2 \%)$, (iii) Internet purchases—origin of sellers (11.4\%), (iv) Internet purchases—collaborative economy (5.4\%), (v) Internet purchases-money spent $(4.2 \%)$, and (vi) financial activities over the Internet (59.8\%). Concerning the HEW scenario, there was no difference among these categories.

The second methodology used was the Likert-scale survey evaluated in the range of 1-5: $1=$ totally disagree, $2=$ disagree, $3=$ neither agree nor disagree, $4=$ agree, and $5=$ completely agree. A critical step in this methodology is represented by the choice of experts. Considering the subject matter, managers were chosen as the category of stakeholders, and it was therefore preferred to focus on practical expertise. The tool used to establish connections with the experts was LinkedIn, a social network mainly used in the development of professional contacts. These phases of the work required time, which was optimized when the goal to be achieved and the knowledge of the people needed were clear. The experts contributed by assigning an evaluation and giving their ideas on the topic analyzed. This part certainly represents a value-added element and is the one that for all 10 experts represented the most time spent on the interview (carried out in March-April 2021). To encourage this approach, the material was sent by email before the interview.

\section{Discussion and Conclusions}

The analysis of this work is part of a larger research project [1]. Specifically, the need to develop additional work stems from the significance associated with defining the methodology and data collection in detail. This aspect is gaining increasing relevance in the literature landscape. We are in a historical phase in which the pandemic has eradicated many certainties. Research has regained a central role. The pandemic has changed many lifestyles, leading consumers to rely even more on online purchases, and in the same way, remote work has become more important. The issue of the relationship between 
sustainability and cybersecurity must be carefully considered. In particular, life cycle analyses demonstrating beneficial effects are required. Digitization certainly saves time, but climate change requires tough choices. Consequently, digital development must be aligned with sustainable development.

In particular, this research project focuses on those aspects of e-commerce that show a greater propensity on the part of European citizens to use this method of purchasing. This work allows a framework to be built that can be replicated in other contexts. The description of the data of a work turns out to be very relevant because it shows us how the results were obtained. On the one hand, the availability of data is fundamental because it allows analysts to interpret such data and identify possible relationships. On the other hand, a methodology applied following a scientific method assigns robustness to the results obtained. The availability of data makes it possible to assess correlations and to identify how variables are related to each other. This is crucial for developing a business strategy in which e-commerce is set to play a crucial role as a sales channel. Moreover, it also induces changes at an organizational level.

In particular, e-commerce is a hot topic and is a preferred channel for the younger generation. In the same way, these very generations are the ones who demand more rights and more sustainability. Sustainable consumption models are not based on approaches that slow economic growth, but on those that combine consumer needs with available resources. In some ways the underlying idea is to minimize waste, an idea that is very well present in production models. However, as a result of crony capitalism, even these models have been seen to focus solely on the economic sphere. E-commerce should not favor production models in places where some workers' rights are not respected or where environmental regulations are less stringent. However, these features would also be potential risks in traditional sales conditions. This is therefore a change of perspective. Likewise, it should not penalize emerging countries, but rather offer them a way to grow economically while respecting social and environmental principles.

This communication makes it possible to propose a method such as the MCDA method, which is well known in the literature because of its flexibility and fields of application. For many, experience in the field is synonymous with knowledge, and the approach proposed in this paper totally agrees. However, the right product is not always sold, and many times the product that is fashionable is sold. On the topic of sustainability, just look at a few years ago, when there were few consumers reading labels and looking for sustainable components. Today everything has changed. However, the strong attention of consumers towards the environment is not enough if the propensity does not translate into an act of purchase. This methodology considers the number of views and of manifestation of interest towards some items. Obviously, this approach cannot be used all the time. For this reason, methods must always be innovative, new ways of assigning weights must be identified, and expert evaluations must be integrated with young talent. Each analysis requires an appropriate choice because there is no universal solution to the various methods. Therefore, the final message of this communication is to provide in detail the framework with which this analysis was carried out in order to be able to replicate it and include it as a methodology in which the selection of weights is attributed to search-engine research. Sustainability has a big task: to provide answers to current problems. This means that e-commerce cannot simply be seen as a mode of sales that can reduce the sales space of some local markets. It is necessary to take note of a change that has already taken place. The data proposed in this paper highlight a significant trend in the European sector, and micro analysis must be conducted at the product level to understand how business strategies must change in order to respond to this external change. Competitiveness also inevitably passes through digital purchasing.

Author Contributions: Conceptualization, D.S.-B.; methodology, I.D.; data curation, R.G.-S. and M.S.M.-S.; writing-original draft preparation, I.D., R.G.-S., M.S.M.-S. and D.S.-B.; writing-review and editing, I.D., R.G.-S., M.S.M.-S. and D.S.-B.; supervision, I.D. All authors have read and agreed to the published version of the manuscript. 
Funding: This research received no external funding.

Institutional Review Board Statement: Not applicable.

Informed Consent Statement: Not applicable.

Data Availability Statement: Not applicable.

Conflicts of Interest: The authors declare no conflict of interest.

\section{References}

1. D'Adamo, I.; González-Sánchez, R.; Medina-Salgado, M.S.; Settembre-Blundo, D. E-Commerce Calls for Cyber-Security and Sustainability: How European Citizens Look for a Trusted Online Environment. Sustainability 2021, 13, 6752. [CrossRef]

2. Calzada, J.; Tselekounis, M. Net Neutrality in a hyperlinked Internet economy. Int. J. Ind. Organ. 2018, 59, 190-221. [CrossRef]

3. Salesforce Salesforce Shopping Index Q1 2021. Available online: https:/ / public.tableau.com/profile/salesforcecommercecloud\# !/vizhome/SalesforceShoppingIndex/SalesforceShoppingIndex (accessed on 7 May 2021).

4. Dupont, B.; Lusthaus, J. Countering Distrust in Illicit Online Networks: The Dispute Resolution Strategies of Cybercriminals. Soc. Sci. Comput. Rev. 2021, 0894439321994623.

5. Settembre-Blundo, D.; González-Sánchez, R.; Medina-Salgado, S.; García-Muiña, F.E. Flexibility and Resilience in Corporate Decision Making: A New Sustainability-Based Risk Management System in Uncertain Times. Glob. J. Flex. Syst. Manag. 2021, $1-26$.

6. Mahmud, P.; Paul, S.K.; Azeem, A.; Chowdhury, P. Evaluating Supply Chain Collaboration Barriers in Small- and Medium-Sized Enterprises. Sustainability 2021, 13, 7449. [CrossRef]

7. Loizia, P.; Voukkali, I.; Chatziparaskeva, G.; Navarro-Pedreño, J.; Zorpas, A.A. Measuring the Level of Environmental Performance on Coastal Environment before and during the COVID-19 Pandemic: A Case Study from Cyprus. Sustainability 2021, $13,2485$. [CrossRef]

8. Paul, S.K.; Moktadir, M.A.; Sallam, K.; Choi, T.-M.; Chakrabortty, R.K. A recovery planning model for online business operations under the COVID-19 outbreak. Int. J. Prod. Res. 2021, 1-23. [CrossRef]

9. Amicarelli, V.; Tricase, C.; Spada, A.; Bux, C. Households' Food Waste Behavior at Local Scale: A Cluster Analysis after the COVID-19 Lockdown. Sustainability 2021, 13, 3283. [CrossRef]

10. Keenan, J.M. COVID, resilience, and the built environment. Environ. Syst. Decis. 2020, 40, 216-221. [CrossRef]

11. D'Adamo, I.; Rosa, P. How do you see infrastructure? Green energy to provide economic growth after COVID-19. Sustainability 2020, 12, 4738. [CrossRef]

12. D'Adamo, I.; Lupi, G. Sustainability and Resilience after COVID-19: A Circular Premium in the Fashion Industry. Sustainability 2021, 13, 1861. [CrossRef]

13. Miceli, A.; Hagen, B.; Riccardi, M.P.; Sotti, F.; Settembre-Blundo, D. Thriving, Not Just Surviving in Changing Times: How Sustainability, Agility and Digitalization Intertwine with Organizational Resilience. Sustainability 2021, 13, 2052. [CrossRef]

14. Vila, T.D.; González, E.A.; Vila, N.A.; Brea, J.A. Indicators of Website Features in the User Experience of E-Tourism Search and Metasearch Engines. J. Theor. Appl. Electron. Commer. Res. 2021, 16, 18-36. [CrossRef]

15. Ferrari, A.M.; Volpi, L.; Settembre-Blundo, D.; García-Muiña, F.E. Dynamic life cycle assessment (LCA) integrating life cycle inventory (LCI) and Enterprise resource planning (ERP) in an industry 4.0 environment. J. Clean. Prod. 2021, $286,125314$. [CrossRef]

16. Kleisiari, C.; Duquenne, M.-N.; Vlontzos, G. E-Commerce in the Retail Chain Store Market: An Alternative or a Main Trend? Sustainability 2021, 13, 4392. [CrossRef]

17. Wang, J.; Gao, X.; Wang, Z. Sustainable Supply Chain Decisions under E-Commerce Platform Marketplace with Competition. Sustainability 2021, 13, 4162. [CrossRef]

18. Crecente, F.; Sarabia, M.; del Val, M.T. Sustainable Entrepreneurship in the 2030 Horizon. Sustainability 2021, 13, 909. [CrossRef]

19. Ronzon, T.; Piotrowski, S.; Tamosiunas, S.; Dammer, L.; Carus, M.; M'barek, R. Developments of economic growth and employment in bioeconomy sectors across the EU. Sustainability 2020, 12, 4507. [CrossRef]

20. D'Adamo, I.; Gastaldi, M.; Rosa, P. Assessing Environmental and Energetic Indexes in 27 European Countries. Int. J. Energy Econ. Policy 2021, 11, 417-423. [CrossRef]

21. Castillo-Giménez, J.; Montañés, A.; Picazo-Tadeo, A.J. Performance and convergence in municipal waste treatment in the European Union. Waste Manag. 2019, 85, 222-231. [CrossRef] [PubMed]

22. Sicilia, M.-A.; García-Barriocanal, E.; Sánchez-Alonso, S. Community Curation in Open Dataset Repositories: Insights from Zenodo. Procedia Comput. Sci. 2017, 106, 54-60. [CrossRef]

23. Sharma, R.K.; Singh, P.K.; Sarkar, P.; Singh, H. A hybrid multi-criteria decision approach to analyze key factors affecting sustainability in supply chain networks of manufacturing organizations. Clean Technol. Environ. Policy 2020, 22, 1871-1889. [CrossRef]

24. Voukkali, I.; Zorpas, A.A. Evaluation of urban metabolism assessment methods through SWOT analysis and analytical hierocracy process. Sci. Total Environ. 2021, 39, 150700. 
25. Karanik, M.; Bernal, R.; Peláez, J.I.; Gomez-Ruiz, J.A. Combining user preferences and expert opinions: A criteria synergy-based model for decision making on the Web. Soft Comput. 2019, 23, 1357-1373. [CrossRef]

26. Brudermann, T.; Mitterhuber, C.; Posch, A. Agricultural biogas plants-A systematic analysis of strengths, weaknesses, opportunities and threats. Energy Policy 2015, 76, 107-111. [CrossRef] 